Winter Meeting - Joint meeting between the Nutrition Society and the Royal Society of Medicine, 11-12 December 2012,

Dietary Strategies for the Management of Cardiovascular Risk

\title{
Total sugar content of takeaway food in Merseyside, UK
}

\author{
I. G. Davies ${ }^{1}$, T. Blackham ${ }^{1}$, J. C. Abayomi ${ }^{1}$, C. Taylor ${ }^{2}$, M. Ashton ${ }^{2}$, R. Long ${ }^{3}$ and L. Stevenson ${ }^{4}$ \\ ${ }^{1}$ Nutrition and Health Research Group, Liverpool John Moores University, Liverpool, L17 6BD, UK, ${ }^{2}$ Knowsley Council, \\ Huyton, L36 9FB, ${ }^{3}$ Liverpool City Council, Liverpool L2 2DH, UK and ${ }^{4}$ Human Nutrition Research Centre, \\ Newcastle University (Singapore), Nanyang Polytechnic,180 Ang Mo Kio Ave 8, Singapore 569830
}

The impact of dietary sugars on risk of cardiometabolic risk and other disease states has been in debate for several decades. Review articles have highlighted the potential risk of fructose on cardiometabolic disease ${ }^{(1)}$ and a recent metaanalysis shows high fructose corn syrup in sweetened beverages probably increases the risk of type 2 diabetes ${ }^{(2)}$. Despite the continuing debate it is important to determine the amount of sugar in food eaten out of the home, which has increased over the last few decades. The European Prospective Investigation into Cancer and Nutrition study showed eating out of the home increases both sugar and fat intake ${ }^{(3)}$; however, the study did not focus on takeaway food from independent establishments. There are no data on the total sugar content of takeaway food from independent establishments in the UK. Therefore, the aim of the present study was to analyse total sugars from popular takeaway foods within various meal categories of independent establishments in Merseyside, UK. Samples of takeaway meals $(n=400)$ were collected from small independent establishments and sent for analysis by an accredited public analyst laboratory. Total sugars were analysed in $\mathrm{g} / 100 \mathrm{~g}$ and calculated g/meal. Meal categories were compared using the Kruskal-Wallis Test. Results revealed a high variability in the amount of sugars within meals and showed a statistically significant difference between meal categories $(p=0.000$, Figure). Chinese meals showed the highest total sugars with up to $158.8 \mathrm{~g}$ per meal. When comparing the various types of cuisine some Chinese and Indian meals (E.G. Sweet \& sour chicken/Chicken tika massala) would be classified as "Red" from the Food Standard Agency traffic light system $(>12.5 \mathrm{~g} / 100 \mathrm{~g})$ (Figure 1).
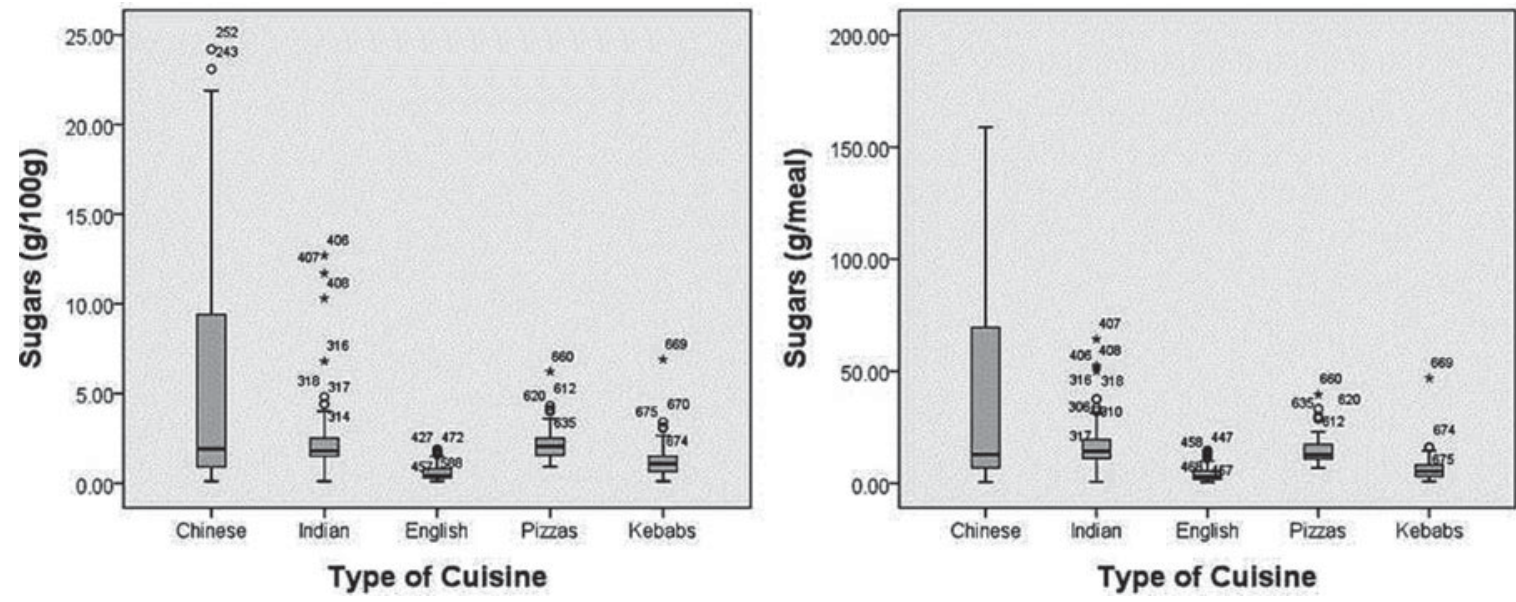

Fig. 1. Total sugars of popular takeaway cuisine from various categories.

The current study shows that some Chinese and Indian popular takeaway meals are very high in sugar content. We have previously shown that certain takeaway food is high in salt ${ }^{(4)}$ and others have shown takeaway food to increase the risk of obesity and components of cardiometabolic risk. Further studies are needed to determine the type of sugar within takeaway food and to investigate consumption patterns of various populations.

1. Stanhope KL (2012) Annu Rev Med. 63, 329-343

2. Sonestedt E, Overby NC, Laaksonen DE et al. (2012) Food Nutr Res 56.

3. Orfanos P, Naska A, Trichopoulou A et al. (2009) Eur J Clin Nutr 63(Suppl 4): S239-S262.

4. Jaworowska A, Blackham T, Stevenson L et al. (2012) Appetite 59, 517-522. 